\title{
Immediate Hypothermia Reduces Cardiac Troponin I After Hypoxic-Ischemic Encephalopathy in Newborn Pigs
}

\author{
XUN LIU, JAMES TOOLEY, ELSE M. LØBERG, M. SAADEH SULEIMAN, AND MARIANNE THORESEN
}

\begin{abstract}
Child Health [X.L., J.T., M.T.], Bristol Heart Institute [M.S.S.], School of Clinical Sciences, University of Bristol, Bristol BS2 8EG, United Kingdom; Department of Pathology [E.M.L.], Ullevaal University Hospital, University of Oslo, Oslo 0407, Norway; Department of Physiology [M.T.], Institute of Basic Medical Sciences, University of Oslo, Oslo 0317, Norway
\end{abstract}

\begin{abstract}
Neonatal hypoxic-ischemic encephalopathy (HIE) is a clinically defined neurological condition after lack of oxygen and often associated with cardiac dysfunction in term infants. Therapeutic hypothermia (HT) after birth is neuroprotective in infants with HIE. However, it is not known whether HT is also cardioprotective. Four newborn pigs were used in the pilot study and a further 18 newborn pigs [randomly assigned to $72 \mathrm{~h}$ normothermia (NT) or $24 \mathrm{~h}$ HT followed by $48 \mathrm{~h} \mathrm{NT}$ ] were subjected to global HIE insults. Serum cTnI was measured before and post the HIE insult. Blood pressure, inotropic support, blood gases, and heart rate (HR) were recorded throughout. Cardiac pathology was assessed from histological sections. Cooling reduced serum cTnI levels significantly in HT pigs by $6 \mathrm{~h}(\mathrm{NT}, 1.36 \pm 0.67$; HT, $0.34 \pm 0.23 \mathrm{ng} / \mathrm{mL} ; p=0.0009)$. After rewarming, from 24 to $30 \mathrm{~h}$ postinsult, $\mathrm{HR}$ and $\mathrm{cTnI}$ increased in the HT group; from $\mathrm{HR}[24 \mathrm{~h}]=117 \pm 22$ to $\mathrm{HR}[30 \mathrm{~h}]=218 \pm 32$ beats $/ \min (p=0.0002)$ and from $\operatorname{cTnI}[24 \mathrm{~h}]=0.23 \pm 0.12$ to $\mathrm{cTnI}[30 \mathrm{~h}]=0.65 \pm 0.53 \mathrm{ng} / \mathrm{mL},(p=0.05)$. There were fewer ischemic lesions on cardiac examination $(37 \%)$ in the HT group compared with the NT group (70\%). HT (24 h) pigs did not have the postinsult cTnI increase seen in NT-treated pigs. There was a trend that HT improved cardiac pathology in this 3-d survival model.

(Pediatr Res 70: 352-356, 2011)
\end{abstract}

$\mathrm{S}$ evere lack of oxygen or perfusion around the time of birth (perinatal asphyxia) leads to hypoxic-ischemic encephalopathy (HIE) and is associated with significant mortality and long-term morbidity. HIE is characterized by clinical and laboratory evidences of brain injury associated with hypoxia and acidosis. Neonatal HIE affects up to 6 per 1000 live births (1). In an autopsy study, cardiac injury is the most prominent organ injury $(62 \%)$ in addition to brain injury (2). Therapeutic hypothermia (HT) after birth (cooling of core temperature to $33-34^{\circ} \mathrm{C}$ for $72 \mathrm{~h}$ ) improves neurological outcome at $18 \mathrm{mo}$ of age in this group of patients (3-5). There is no direct evidence to show that therapeutic HT is also cardioprotective in newborns with HIE. In asphyxiated cooled newborns, HT has been shown to induce mild sinus bradycardia and a slight increase in mean arterial blood

Received February 22, 2011; accepted April 6, 2011.

Correspondence: Marianne Thoresen, M.D., Ph.D., St. Michael Hospital, Level D, Child Health, Bristol BS2 8EG, United Kingdom; e-mail: marianne.thoresen@bristol.ac.uk

Supported by The Welcome Trust (UK) and Laerdal Foundation for Acute Medicine (Norway). pressure (MABP) (6). Whether such cardiovascular changes confer protection against hypoxia is not presently known.

Cardiac troponins (cTnT and cTnI) are proteins released from injured cardiomyocytes. They are established biological markers with high sensitivity to diagnose myocardial cell injury in adults $(7,8)$ and neonates $(9,10)$. Furthermore, the level of cTnI in cord blood has been suggested to predict early mortality after perinatal asphyxia (11). The aim of this study is to determine whether immediate cooling after the acute insult is cardioprotective in an established hypoxic-ischemic newborn pig model (12).

\section{METHODS}

All animal work was carried out and approved under Home Office license in accordance with UK guidelines. This study was approved by the Animal Ethical Review Panel at the University of Bristol. Twenty-two crossbred Landrace large white newborn pigs of either sex, median (interquartile range, IQR) age of $18 \mathrm{~h}(9-20)$, and median weight of $1.64(1.4-1.8) \mathrm{kg}$ were used in this study. Four pigs were used in the pilot study and 18 pigs were used in the experimental study [normothermia $(\mathrm{NT})=10$, HT $=8$ ].

Global hypoxic-ischemic insult. All animals were subjected to our established global hypoxic-ischemic insult (HI) $(12,13)$. Briefly, unrestrained animals were anesthetized with $4.0 \%$ halothane and nitrous oxide $\left(\mathrm{N}_{2} \mathrm{O}\right)$ in a closed Perspex box followed by intubation and mechanical ventilation with halothane $0.7 \%, \mathrm{~N}_{2} \mathrm{O} 65 \%$, and oxygen $\sim 35 \%$. Ventilator settings were adjusted to maintain end-tidal carbon dioxide around $5.3 \pm 0.3 \mathrm{kPa}$ during the study, but $\mathrm{PCO}_{2}$ were kept unadjusted during the 45-min insult. Hypoxicischemic injury was introduced by rapidly reducing the fraction of inspired oxygen concentration $\left(\mathrm{FiO}_{2}\right)$ to $4-6 \%$ in a gas mixture (nitrogen and oxygen) for $45 \mathrm{~min}$. Consequently, the continuously recorded EEG became depressed $(<7 \mu \mathrm{V})$ for at least $20 \mathrm{~min}(12)$ accompanied by hypotension (mean blood pressure $<40 \mathrm{~mm} \mathrm{Hg}$ ). Animals were resuscitated with appropriate $\mathrm{FiO}_{2}$ (starting from air), avoiding hyperoxia, to maintain transcutaneous oxygen saturation $\left(\mathrm{TcSaO}_{2}\right)$ between 95 and $98 \%$ (Masimo SET, Masimo Corporation, CA). Previously (12), we resuscitated pigs with $100 \% \mathrm{O}_{2}$ and corrected acidosis with bicarbonate. Since 2003 (13), we have resuscitated pigs with air and followed clinical guidelines increasing in steps of $+5 \% \mathrm{O}_{2}$ every $90 \mathrm{~s}$ if the saturation did not improve. Typically, no more than $30 \% \mathrm{O}_{2}$ was used to resuscitate a pig after the insult.

Before and during the insult, newborn pigs were kept NT at $39^{\circ} \mathrm{C}$ which is a normal body temperature for newborn pigs $(14,15)$. After the insult, pigs were kept either NT for $72 \mathrm{~h}$ or HT at $34.5^{\circ} \mathrm{C}$ for the first $24 \mathrm{~h}$ followed by $48 \mathrm{~h}$ NT until killed at $72 \mathrm{~h}$ postinsult.

Pilot experiments. Newborn pigs, unlike humans, have low $\mathrm{Hb}$ at birth $(\sim 8 \mathrm{~g} / \mathrm{dL})$ and frequent blood sampling will make them anemic. Therefore, to decide the minimum frequency and the best sampling time-points for cTnI after the insult, a small pilot experiment (four pigs with mild HI insult) with frequent blood sampling (baseline, $1,3,6,12,24,48$, and $72 \mathrm{~h}$ postinsult) at

Abbreviations: cTn, cardiac troponin; HIE, hypoxic-ischemic encephalopathy; HI, hypoxic-ischemic insult; HR, heart rate; HT, hypothermia; IQR, interquartile range 
NT were carried out. In Figure 1, cTnI was measured before the insult and at the set time points after the insult and cTnI visually peaks at $3-6 \mathrm{~h}$. We chose to measure the first $\mathrm{cTnI}$ at $6 \mathrm{~h}$ in our main study to minimize sampling frequency to 6 including the peak cTnI value.

Anesthesia. Umbilical arterial and venous catheters were inserted to allow for continuous MABP monitoring (Philips, USA), repeated blood sampling, and infusion of fluids and drugs. After the insult, inhalation anesthesia was changed to i.v. anesthesia. Bolus doses of Propofol (4 mg/kg) and Fentanyl $(30 \mu \mathrm{g} / \mathrm{kg}$ ) were followed by maintenance infusions of $4-12 \mathrm{mg} / \mathrm{kg} / \mathrm{h}$ Propofol and $10 \mu \mathrm{g} / \mathrm{kg} / \mathrm{h}$ Fentanyl. Twenty-four hours after the insult (equivalent to the end of cooling), maintenance anesthesia was stopped, rewarming started in the HT groups, and pigs from both groups were allowed to wake up and be extubated when breathing independently. We have previously shown that pigs were stressed with high heart rate (HR) and cortisol levels if kept awake and cold during HT treatment (16).

The cumulative amount of Propofol and Fentanyl given in the HT and NT groups did not differ. Fentanil was given at $10 \mu \mathrm{g} / \mathrm{kg} / \mathrm{h}$ in both groups and propofol at $4.9 \mathrm{mg} / \mathrm{kg} / \mathrm{h}$ in the HT and $5.6 \mathrm{mg} / \mathrm{kg} / \mathrm{h}$ in the NT group.

Therapeutic HT and NT. Pigs in the NT group were maintained throughout the study period at the target rectal temperature $39.0 \pm 0.2^{\circ} \mathrm{C}$ for $72 \mathrm{~h}$. Pigs in the HT group were cooled immediately after the insult for $24 \mathrm{~h}$ using a cooling cap (The Cool Care System; Natus, Seattle, USA) combined with mild body $\mathrm{HT}$ to rectal temperature $34.5^{\circ} \mathrm{C}$ for $24 \mathrm{~h}$. An overhead infant heater was used to ensure a stable core temperature $(4,17)$. At the end of the HT treatment, pigs were rewarmed over $6 \mathrm{~h}$ to a rectal temperature of $39^{\circ} \mathrm{C}$. All pigs received standard intensive care. Blood pressure, HR, and continuous EEG were monitored. If a single seizure (both clinical and electrical) lasted more than $10 \mathrm{~min}$, a loading dose of phenobarbitone at $20 \mathrm{mg} / \mathrm{kg}$ was given over $20 \mathrm{~min}$. A second dose of phenobarbitone was given if there was no effect within $60 \mathrm{~min}$ from the first dose. A third anticonvulsant, clonazepam, was given at $100 \mu \mathrm{g} / \mathrm{kg}$ if needed. Most pigs had electrical seizures (75\% in the HT group and $90 \%$ in the NT group). The total duration (median, IQR) of EEG seizures is $42(9-262) \mathrm{min}$ in the HT group and $348(250-423) \mathrm{min}$ in the NT group during the 72-h experimental period. No HT pigs needed any anticonvulsant as the seizure epochs were $<10 \mathrm{~min}$. Eight of 10 NT pigs were treated with anticonvulsants. Five of them received one dose of phenobarbitone, two required the second dose of phenbarbitone, and one pig needed additional clonazepam. Four of $10 \mathrm{NT}$ pigs received inotropic support and also required anticonvulants.

$M A B P$ and $H R$ monitoring. Continuous MABP was measured from the umbilical artery catheter. During the insult, no lower limit for MABP was set (unless it was associated with increasing bradycardia and prone to cardiac arrest); otherwise, a MABP $<40 \mathrm{~mm} \mathrm{Hg}$ was treated with a $10 \mathrm{~mL} / \mathrm{kg}$ bolus of $0.9 \%$ normal saline followed, if the MABP remained low, by a $10 \mathrm{~mL} / \mathrm{kg}$ bolus of $5 \%$ human albumin. If hypotension continued, inotropic support was commenced with an infusion of dopamine (range, 5-20 $\mu \mathrm{g} / \mathrm{kg} / \mathrm{min}$ ) and then (if necessary) an infusion of noradrenaline (range, 0.05-0.1 $\mu \mathrm{g} / \mathrm{kg} / \mathrm{min}$ ). Inotropic support was weaned if the MABP of the pig remained above $45 \mathrm{~mm}$ $\mathrm{Hg}$ for $60 \mathrm{~min}$. HR was calculated from electrocardiographic (ECG) signals

cTnI analysis. Blood samples for cTnI measurements were collected at baseline (30 min before $\mathrm{HI})$ and at predesigned time points after $\mathrm{HI}(6,12,24$, 30 , and $48 \mathrm{~h}$ postinsult). Serum was stored at $-80^{\circ} \mathrm{C}$ until analyzed. Concentrations of cTnI were measured using the ACCESS Immunoassay system (Beckman Instruments Inc., Buckinghamshire, UK) which has a low detection limit of $0.01 \mathrm{ng} / \mathrm{mL}$.

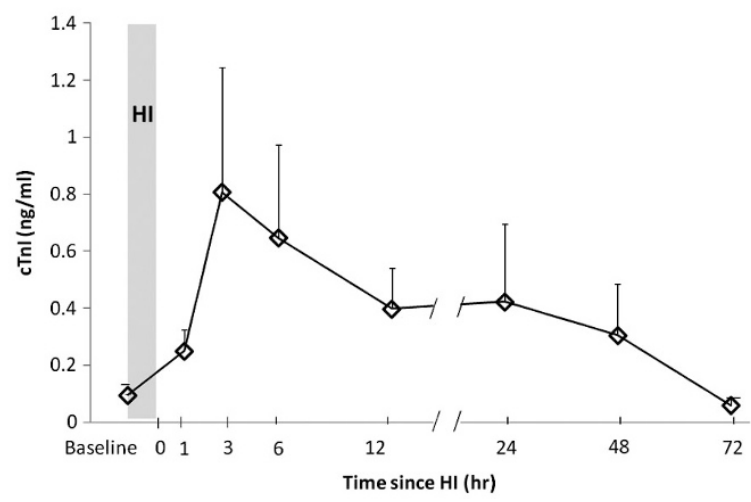

Figure 1. Frequent serum cardiac troponin I levels (mean \pm SEM) in four pilot pigs that underwent 45 min of global hypoxia-ischemia and then kept at normothermia for $72 \mathrm{~h}$ to characterize the time course of cTnI changes.
Histology assessment. Animals were euthanized $72 \mathrm{~h}$ after HI, and the brains were perfusion-fixed using $4 \%$ phosphate-buffered formaldehyde (PBF). The hearts were immersion fixed and stored in $4 \%$ PBF. The right brain hemisphere of each pig was cut into 13,3-mm thick coronal blocks, and the heart was cut into five, 3 -mm thick transverse blocks. Specimens were then dehydrated and paraffin-embedded. Sections $(6 \mu \mathrm{m})$ were cut and stained with hematoxylin and eosin.

The clinical pathologists who assessed the sections under light microscopy were blinded to the treatment groups. A modified scoring system $(18,19)$ was used for the heart based on the type and the total number of lesions counted in five cross sections from each heart. The brain injury score system in our model (nine-step with intervals of 0.5 from 0.0 to 4.0 from six brain regions) has been presented and validated previously (12).

Statistical analysis. Descriptive data are presented with mean \pm SD or median $\pm \mathrm{IQR}$. A $t$-test was performed to compare means of two cTnI levels The " $N-1$ " $\chi^{2}$ test was used to compare cardiac pathology data (20). Linear regression was carried out to define the relationships between serum cTnI levels and heart or brain pathology scores using SPSS v16.

\section{RESULTS}

The severity of the HI insult was similar in both groups defined by the duration of depressed (low amplitude $<7 \mu \mathrm{V}$ ) EEG, the $\mathrm{pH}$ and base excess (BE) at the end of $\mathrm{HI}$, and percentage of time the blood pressure decreased below $40 \mathrm{~mm}$ $\mathrm{Hg}$ during HI (13). The average MABP during the insult was $38 \pm 5.1 \mathrm{~mm} \mathrm{Hg}$ in the NT and $33 \pm 4.5 \mathrm{~mm} \mathrm{Hg}$ in the HT pigs. Values of arterial $\mathrm{pH}$ and $\mathrm{BE}$ at the end of $\mathrm{HI}$ were similar in the NT and HT groups: $7.01 \pm 0.036$ in NT compared with $7.11 \pm 0.062$ in HT and $-21.4 \pm 2.3$ in the NT versus $-24.7 \pm 3.1 \mathrm{mM}$ in the HT pigs. Demographic data are shown in Table 1.

cTnI release in hypoxic pigs. Baseline cTnl levels were similar between the NT and HT groups: $0.14(0.07-0.33) \mathrm{ng} / \mathrm{mL}$ in NT pigs versus $0.13(0.06-0.25) \mathrm{ng} / \mathrm{mL}$ in HT pigs $(p=$ 0.80 ). It is also consistent with our pilot experiment which indicated that the cutoff value of cTnI for a newborn pig is below $0.2 \mathrm{ng} / \mathrm{mL}$. At 6-h postinsult, a significant increase in cTnI levels from baseline was seen in both NT and HT groups (Fig. 2). Importantly, the peak increase was three times greater in the NT group than the HT group $(\mathrm{cTnI}[\mathrm{NT}]=1.36 \pm 0.67 \mathrm{ng} / \mathrm{mL}$ and $\mathrm{cTnI}[\mathrm{HT}]=0.34 \pm 0.23 \mathrm{ng} / \mathrm{mL} ; p=0.0009)$. By the end of $6 \mathrm{~h}$ rewarming and discontinuation of anesthesia $(30 \mathrm{~h}$ after the insult), there was a transient increase ( $p=0.05$; HT group) in cTnI in both groups before falling back to baseline levels at $48 \mathrm{~h}$ after insult. There was a concomitant $100 \%$ increase in HR in the HT group between 24 and $30 \mathrm{~h}$ during rewarming.

Table 1. Demographic values in the two experimental groups during the insult

\begin{tabular}{|c|c|c|c|}
\hline \multirow[b]{2}{*}{ Group } & \multicolumn{2}{|c|}{ Treatment } & \multirow[b]{2}{*}{$p$} \\
\hline & $\begin{array}{l}\text { Normothermia } \\
\quad(n=10)\end{array}$ & $\begin{array}{l}\text { Hypothermia } \\
\quad(n=8)\end{array}$ & \\
\hline Age $[\mathrm{h}$, median (IQR)] & $18(6-30)$ & $13.5(2-24)$ & 0.31 \\
\hline Weight $[\mathrm{kg}$, median IQR)] & $1.63(1.09-2.17)$ & $1.60(1.29-1.91)$ & $>0.5$ \\
\hline $\begin{array}{l}\text { Duration of aEEG }<7 \mu \mathrm{V} \\
\text { during } \mathrm{HI}(\mathrm{min})\end{array}$ & $29.7 \pm 9$ & $25.2 \pm 8.4$ & $>0.5$ \\
\hline $\begin{array}{l}\mathrm{pH} \text { at the end of } \mathrm{HI} \\
(\text { mean } \pm \mathrm{SD})\end{array}$ & $7.01 \pm 0.036$ & $7.11 \pm 0.062$ & 0.18 \\
\hline $\begin{array}{l}\mathrm{BE} \text { at the end of } \mathrm{HI} \\
(\mathrm{mmol} / \mathrm{L}, \text { mean } \pm \mathrm{SD})\end{array}$ & $-21.4 \pm 2.3$ & $-24.7 \pm 3.1$ & $>0.5$ \\
\hline $\begin{array}{l}\text { MABP during the insult } \\
(\mathrm{mm} \mathrm{Hg})\end{array}$ & $38 \pm 5.1$ & $33 \pm 4.5$ & $>0.5$ \\
\hline
\end{tabular}

aEEG, amplitude-integrated EEG. 


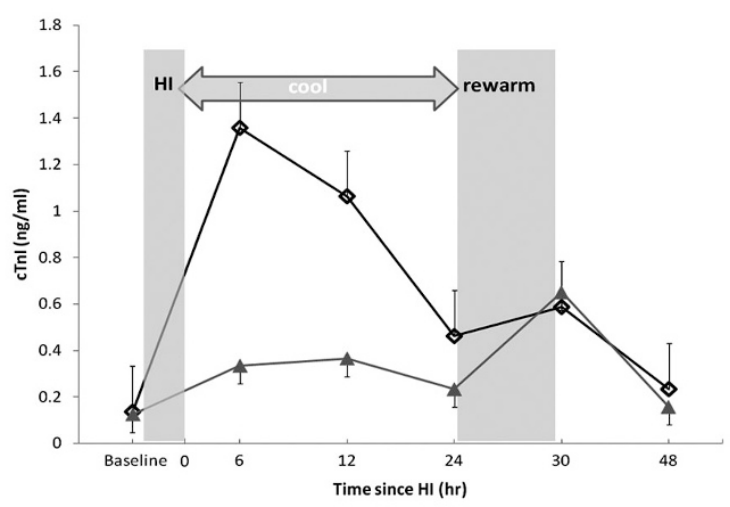

Figure 2. Mean \pm SEM cardiac troponin I levels in animals treated with normothermia ( $\diamond ; n=10)$ and hypothermia $(\boldsymbol{\Delta} ; n=8)$ at baseline, $6,12,24$, 30 , and $48 \mathrm{~h}$ after the 45 -min hypoxic-ischemia insult.

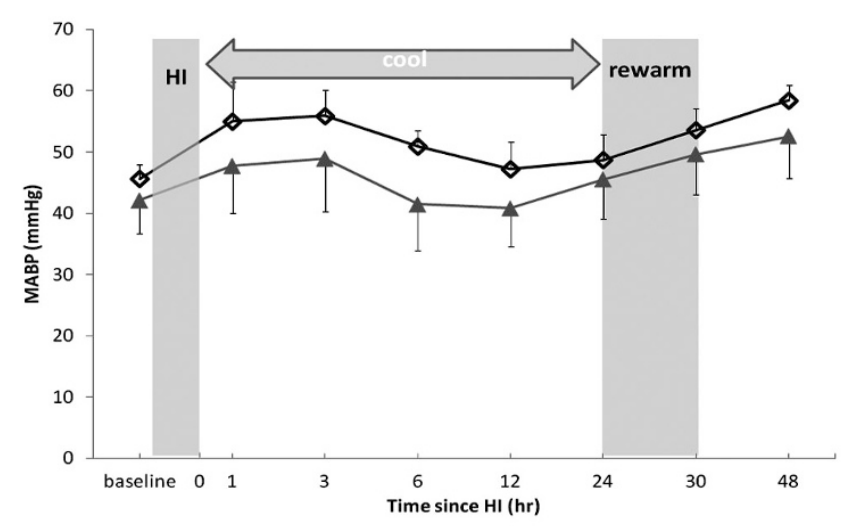

Figure 3. Mean \pm SEM blood pressure in animals treated with normothermia $(\diamond ; n=10)$ and hypothermia $(\boldsymbol{\Lambda} ; n=8)$ at baseline, 3, 6, 12, 24, 30, and $48 \mathrm{~h}$ after the $45-\mathrm{min}$ hypoxic-ischemia insult.

\section{Blood pressure and HR in NT- and HT-treated newborn} pigs. There was no statistical difference in MABP between NT- and HT-treated animals (Fig. 3). There was no difference in the use of inotropic drugs (dopamine and noradrenaline) between the two groups, 50\% HT and 40\% NT pigs received inotropic support. The average of duration of inotropic support was $1092 \pm 419 \mathrm{~min}$ in the HT group and $1690 \pm 1092 \mathrm{~min}$ in the NT group $(p=0.4)$. The accumulated dopamine dosage was $14.4 \pm 6.3 \mu \mathrm{g} / \mathrm{kg} / \mathrm{min}$ in the HT group and $15.6 \pm 9.6$ $\mu \mathrm{g} / \mathrm{kg} / \mathrm{min}$ in the NT group $(p=0.4)$. Only one HT pig had noradrenaline for $5 \mathrm{~h}$.

There was a significant difference in the HR between the NT and HT groups during the first $24 \mathrm{~h}$ (HT period, $p<0.001$; Fig. $4 A)$. There was a dramatic increase in HR during rewarming in the HT group $(\mathrm{HR}[24 \mathrm{~h}]=117 \pm 22$ beats $/ \mathrm{min} ; \mathrm{HR}[30 \mathrm{~h}]=$ $218 \pm 32$ beats $/ \mathrm{min} ; p=0.0002$ ) but no increase in the NT group at $24-30 \mathrm{~h}$ when anesthesia was discontinued in both groups (Fig. 4B). We did not find any major adverse events such as hypotention, bradycardia, arrhythmia, and pulmonary hypertension in this study. There was no increased oxygen requirement in the cooled group. This is consistent with a recent meta-analysis of three large neonatal cooling trials (21).

Effect of HT on myocardial structural changes during $\boldsymbol{H I E}$. Histological injury of the heart was observed in $70 \%$ of the NT group compared with $37 \%$ in the HT group. There
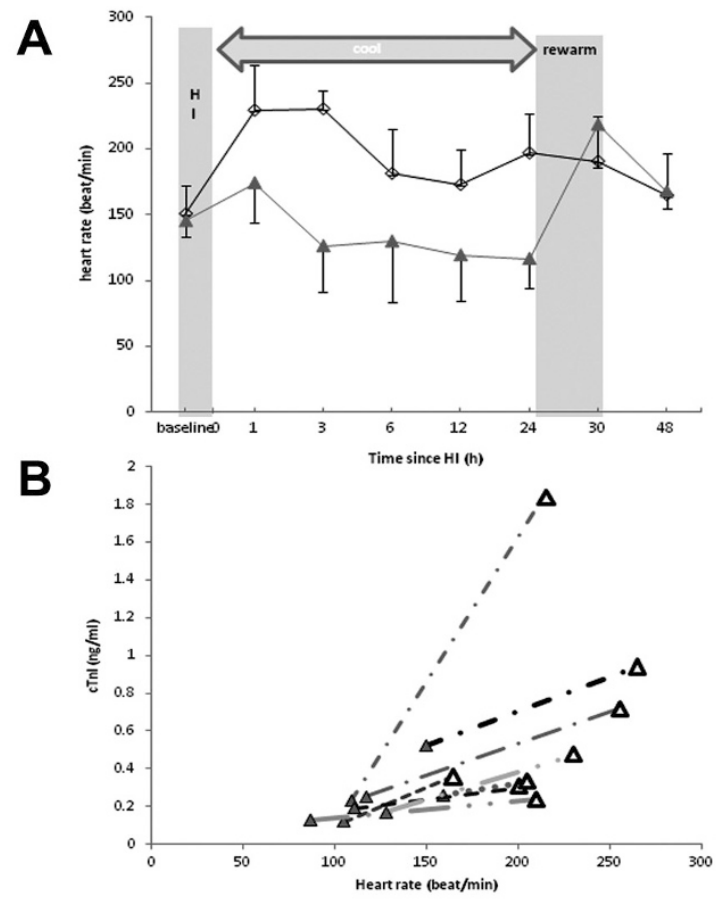

Figure 4. (A) Mean \pm SEM HR in animals treated with normothermia $(\diamond$; $n=10)$ and hypothermia $(\boldsymbol{\Delta} ; n=8)$ at baseline, 3, 6, 12, 24, 30, and $48 \mathrm{~h}$ after the 45-min hypoxic-ischemia insult. (B) Correlation between HR and cardiac troponin I at the end of cooling (24 h, $\mathbf{\Delta})$ and end of rewarming (30 $\mathrm{h}, \triangle$ ) in the cooled group (HT, $n=8$ ). Different styles of lines linking two time points ( 24 and $30 \mathrm{~h}$ ) are used to separate individual changes in animals.

were no large infarcts, only multiple smaller lesions. These lesions consisted of a varying amount of necrotic muscle fibers surrounded by a cellular reactive reaction. Most (89\%) lesions were localized subendocardially in the right ventricle regardless of treatments (Fig. 5A).

There was a trend for having reduced number of lesions in animals treated with HT compared with NT ( $p=0.07$; Fig. $5 B$ ). The 6-h post-HI cTnI level correlated well with the number of lesion in the heart in the NT groups but not in the HT group $\left(r^{2}[\mathrm{NT}]=0.35, p=0.07 ; r^{2}[\mathrm{HT}]=0.019, p=\right.$ 0.74; Fig. 5B).

The 6-h post-HI cTnI concentration correlated with brain pathology score at $72 \mathrm{~h}$ when combining both groups but not with individual treatment groups $\left(r^{2}[\mathrm{NT}+\mathrm{HT}]=0.39, p=0.005\right.$; $r^{2}[\mathrm{NT}]=0.26, p=0.13 ; r^{2}[\mathrm{HT}]=0.036, p=0.65$; Fig. 6).

\section{DISCUSSION}

This work presents, for the first time, that therapeutic HT after hypoxia-ischemia in newborn pigs is also cardioprotective in our established newborn pig global HIE model. This global injury model of neonatal brain injury with multiorgan failure was used in neuroprotective cooling research $(13,16,22-24)$ and contributed toward successful clinical trials $(3,4)$. Increasingly, therapeutic HT is becoming standard of care in treating HIE infants worldwide (25). HT has proven to be neuroprotective, but there is no sufficient evidence demonstrating whether HT confers cardioprotection in intensive care patients. Some concern relates to work on adults where HT 


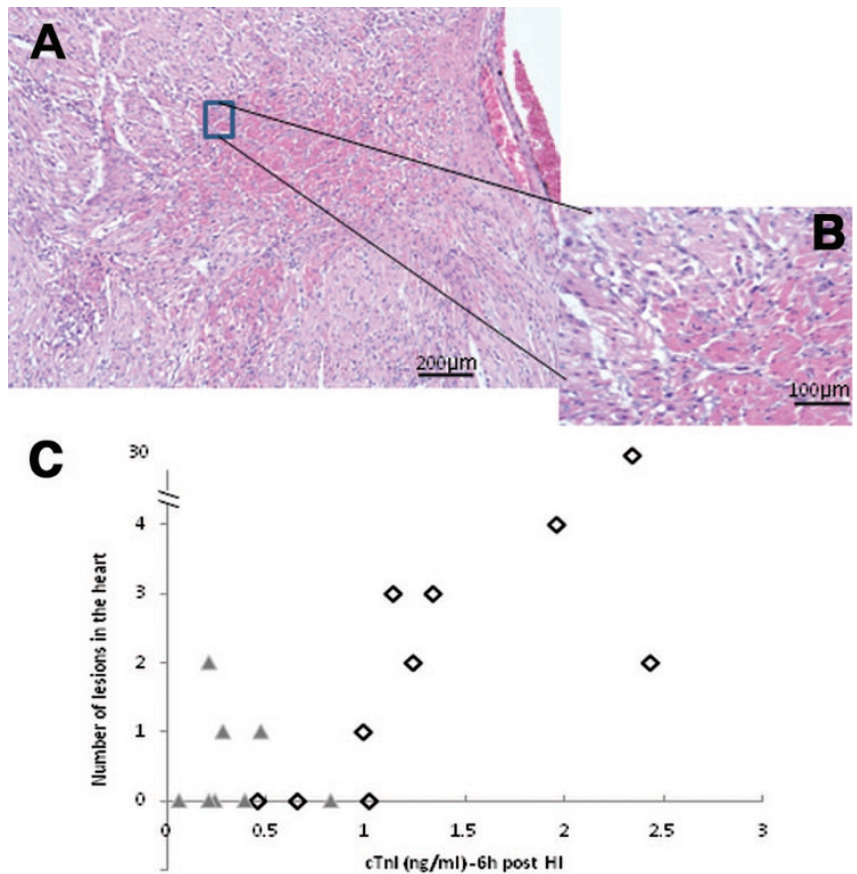

Figure 5. $(A, B)$ Representative images of an injured newborn pig heart at magnifications at $\times 200(A$, bar $=200 \mu \mathrm{m})$ and magnifications at $\times 400(B$, bar $=100 \mu \mathrm{m})$. The magnified image $(B)$ on the right bottom of the corner represents a small myocardial infarct with eosinophilic myocytes with pyknotic or disintegrated nuclei. $(C)$ The correlation between the level of cardiac troponin I at $6 \mathrm{~h}$ after $\mathrm{HI}$ and the number of pathologcal lesions in the heart in the normothermia group. Normothermia $(\diamond ; n=10)$; hypothermia $(\boldsymbol{\Lambda} ; n=8)$.

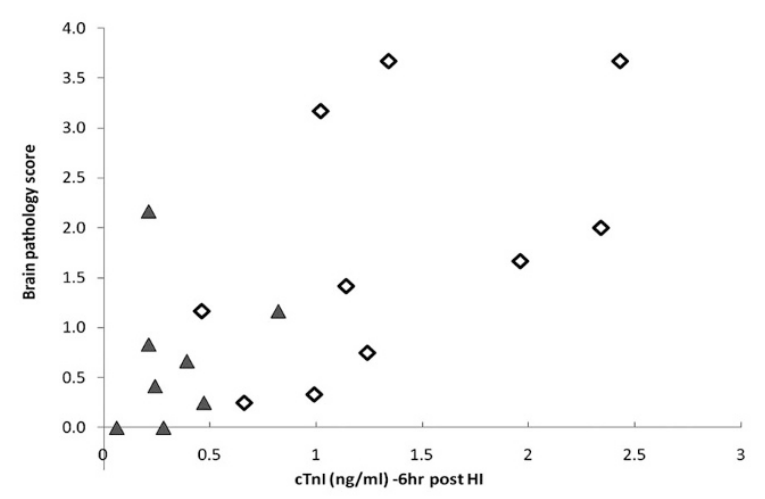

Figure 6. The levels of cardiac troponin I at $6 \mathrm{~h}$ after the insult are plotted against the average brain pathology score at $72 \mathrm{~h}$ after the insult. Normothermia $(\diamond ; n=10)$; hypothermia $(\mathbf{\Lambda} ; n=8)$.

treatment causes hypotension (26). However, hypotension during $3 \mathrm{~d}$ of HT treatment was not found in three large neonatal clinical HT trials with appropriate care (3-5).

The significant HR reduction in the cooling group may confer reduced stress and be an indirect measure of reduced energy and metabolic demand in our study. Our study has followed a strict protocol to treat hypotension and to avoid other adverse incidents. We have introduced background sedation which reduce the stress level during HT treatment (13). We have also previously shown that HT and sedations per se do not increase the apoptotic cell death in our model (27). These may all contribute to hypothermic cardioprotection. We did not see the differences in MABP and in use of inotropics in the first $3 \mathrm{~d}$ between the two groups. However, there is a trend of a lower MABP in the HT group. In this study, there was only one HT pig which had severe and also drug resistant hypotension during the whole experimental period. Despite this long-lasting low MABP, this HT pig only had two ischemic lesions in the heart. The rest of the HT pigs all had MABP $>40 \mathrm{~mm} \mathrm{Hg}$ during the experiment. Clinically, maintained MABP and reduced use of inotropic support are often noted as signs of cardiac recovery. We did see reduced cTnI levels and improved pathology in the heart in the cooled group which indicated the hypothermic cardiac protection. It is not possible to obtain the data on heart pathology clinically but cTnI can be used as an early marker to describe injury and cardiac recovery in asphyxia infants.

Cardiac troponin I as a cardiac biomarker is well established in adults and has been recognized as not only a diagnostic but prognostic marker (8). However, its potential application in neonatal medicine has not been fully explored. Cord cTnI was suggested as a good early predicator of severity of HIE in term infants (11). The levels of cTnI are barely detectable in healthy adults and increases in cTnI above the 99th percentile reference limit are considered an indication of myocardial injury. This limit has been reported as low as 0.03 $\mathrm{ng} / \mathrm{mL}$ in adults (28). Comparing cTnI in adults with infants, higher baseline levels of $\mathrm{cTnI}(>0.03 \mathrm{ng} / \mathrm{mL})$ are observed in the first 3 mo of life (29). According to our pilot study and the specific cTnI assay used, we have set the normal range of cTnI for a new born pig below $0.2 \mathrm{ng} / \mathrm{mL}$.

In animal studies, it has been reported that the level of cTnI starts to increase by $30 \mathrm{~min}$ with a peak value at $3 \mathrm{~h}$ after cardiac arrest in adult pigs (30) and started to increase from 0.5 to $1 \mathrm{~h}$ after induced cardiac injury and normalized within $48 \mathrm{~h}$ after the insult in adult rodents (31). Our data confirm this rapid release of cTnI after acute injury as we observed the first increase in cTnI at $1 \mathrm{~h}$ after a 45 -min global (Fig. 1) insult with a peak around 3-6 $\mathrm{h}$ in the pilot study. The time course of cTnI release in our normothermic animals is similar to that seen in older children after acute myocardial injury (32). We have also shown the level of cTnI normalized in both treated groups $48 \mathrm{~h}$ after the insult. Similar data for cooled/noncooled newborns are only available at the age of $72 \mathrm{~h}$ (33), where there was also no difference observed between two groups. In this randomized study, we showed earlier time points after an acute injury. There was a nearly 9-fold cTnI increase $6 \mathrm{~h}$ after $\mathrm{HI}$, and no increase in HR or cTnI in the NT pigs when i.v. anesthesia was ended during the rewarming period. The findings from the HT group are different. In these anesthetized cooled pigs, the cTnI was much lower in the cooled group compared with NT group. This suggests that HT may provide cellular protection to the heart. Because of small numbers, we did not reach significance when comparing the pathology results. Neonatal hearts, different from adult hearts, rely on anaerobic metabolism. They have high glycogen stores. Therefore, neonatal heart has increased tolerance to transient hypoxic-ischemic damage (34). Cardiac troponin I is a more sensitive biomarker compared with cardiac pathology. We may see the transient increase in cTnI without permanent damage in the heart. In addition, neonatal hearts is better at 
cellular repair than adult hearts. This may explain that we only see smaller lesions in a subset of animals but a huge increase of $\mathrm{cTnI}$ level soon after the insult. During fast rewarming (near $0.8^{\circ} \mathrm{C} / \mathrm{h}$ ) in the HT group, the HR almost doubled, and there was a significant increase in cTnI which may indicate cardiac stress. The NT pigs had longer durations of seizures. Seizure activity may also increase HR and cardiac stress. Slow rewarming rates may be beneficial for the heart.

In the normothermic newborn pigs after a $\mathrm{HI}$ insult, we find a strong relationship between myocardial damage and peak cTnI levels. Prospective clinical data are needed to examine whether cTnI is a valid predictor of neurological/cardiac outcome for HIE infants after therapeutic HT.

There are some limitations to our study. The experimental insult was not carried out around the time of birth but within $24 \mathrm{~h}$ of age. To introduce $\mathrm{HI}$ in our newborn pig model, pigs were ventilated and sedated with halothane for $45 \mathrm{~min}$. Clinically, the fetus or newborn may have different types and degree of injury due to the time of the onset and the duration of the insult(s). Some infants may have one prolonged systemic HI injury as demonstrated in our model and others may have a few but shorter episodes of insults that may affect the heart differently. Most injuries were seen in the right ventricle which is a typical location in the newborn stressed heart (35). We used 24-h cooling treatment in this study which is different from $72 \mathrm{~h}$ applied clinically. Different animal species require different effective cooling durations. We have previously shown that 24-h cooling provides better neuroprotection than $12 \mathrm{~h}$ cooling and significant neuroprotection than NT (36) in this model. Therefore, we believe that 24-h cooling is the optimal cooling duration in newborn pigs.

In conclusion, mild immediate HT as a postinsult neuroprotective intervention may also protect the heart, in particular, if conducted with appropriate clinical management, a slow rewarming rate, and adequate sedation during cooling therapy.

Acknowledgments. We are grateful to Olympic Medical for the CoolCap system, SLE Ltd. for lending us ventilators and Ohmeda Ltd. for the Giraffe incubator.

\section{REFERENCES}

1. Shankaran S 2009 Neonatal encephalopathy: treatment with hypothermia. J Neurotrauma $26: 437-443$

2. Barnett CP, Perlman M, Ekert PG 1997 Clinicopathological correlations in postasphyxial organ damage: a donor organ perspective. Pediatrics 99:797-799

3. Azzopardi DV, Strohm B, Edwards AD, Dyet L, Halliday HL, Juszczak E, Kapellou O, Levene M, Marlow N, Porter E, Thoresen M, Whitelaw A, Brocklehurst P 2009 Moderate hypothermia to treat perinatal asphyxial encephalopathy. N Engl J Med 361:1349-1358

4. Gluckman PD, Wyatt JS, Azzopardi D, Ballard R, Edwards AD, Ferriero DM, Polin RA, Robertson CM, Thoresen M, Whitelaw A, Gunn AJ 2005 Selective head cooling with mild systemic hypothermia after neonatal encephalopathy: multicentre randomised trial. Lancet 365:663-670

5. Shankaran S, Laptook AR, Ehrenkranz RA, Tyson JE, McDonald SA, Donovan EF, Fanaroff AA, Poole WK, Wright LL, Higgins RD, Finer NN, Carlo WA, Duara S, Oh W, Cotten CM, Stevenson DK, Stoll BJ, Lemons JA, Guillet R, Jobe AH 2005 Whole-body hypothermia for neonates with hypoxic-ischemic encephalopathy. N Engl J Med 353:1574-1584

6. Lista G, Pogliani L, Fontana P, Castoldi F, Compagnoni G 2004 Cardiovascular and respiratory status in mechanically ventilated asphyxiated term infants: comparison between hypothermic and control group. Acta Biomed 75:107-113

7. Falahati A, Sharkey SW, Christensen D, McCoy M, Miller EA, Murakami MA, Apple FS 1999 Implementation of serum cardiac troponin I as marker for detection of acute myocardial infarction. Am Heart J 137:332-337
8. Inbar R, Shoenfeld Y 2009 Elevated cardiac troponins: the ultimate marker for myocardial necrosis, but not without a differential diagnosis. Isr Med Assoc J 11:50-53

9. Rajakumar PS, Bhat BV, Sridhar MG, Balachander J, Konar BC, Narayanan P, Chetan G 2008 Cardiac enzyme levels in myocardial dysfunction in newborns with perinatal asphyxia. Indian J Pediatr 75:1223-1225

10. Suleiman MS, Lucchetti V, Caputo M, Angelini GD 1999 Short periods of regional ischaemia and reperfusion provoke release of troponin I from the human hearts. Clin Chim Acta 284:25-30

11. Türker G, Babaoğlu K, Gökalp AS, Sarper N, Zengin E, Arisoy AE 2004 Cord blood cardiac troponin I as an early predictor of short-term outcome in perinatal hypoxia. Biol Neonate 86:131-137

12. Thoresen M, Haaland K, Loberg EM, Whitelaw A, Apricena F, Hanko E, Steen PA 1996 A piglet survival model of posthypoxic encephalopathy. Pediatr Res 40:738748

13. Tooley JR, Satas S, Porter H, Silver IA, Thoresen M 2003 Head cooling with mild systemic hypothermia in anesthetized piglets is neuroprotective. Ann Neurol 53:65-72

14. Mount LE, Rowell JG 1960 Body size, body temperature and age in relation to the metabolic rate of the pig in the first five weeks after birth. J Physiol 154:408-416

15. Tuchscherer M, Puppe B, Tuchscherer A, Tiemann U 2000 Early identification of neonates at risk: traits of newborn piglets with respect to survival. Theriogenology 54:371-388

16. Thoresen M, Satas S, Loberg EM, Whitelaw A, Acolet D, Lindgren C, Penrice J, Robertson N, Haug E, Steen PA 2001 Twenty-four hours of mild hypothermia in unsedated newborn pigs starting after a severe global hypoxic-ischemic insult is not neuroprotective. Pediatr Res 50:405-411

17. Tooley J, Satas S, Eagle R, Silver IA, Thoresen M 2002 Significant selective head cooling can be maintained long-term after global hypoxia ischemia in newborn piglets. Pediatrics 109:643-649

18. Andresen JH, Carlsen B, Solberg R, Morkrid L, Goverud IL, Loberg EM, Saugstad OD 2009 Newborn piglets exposed to hypoxia after nicotine or saline pretreatment: long-term effects on brain and heart. J Matern Fetal Neonatal Med 22:161-168

19. Satas S, Loberg EM, Porter H, Whitelaw A, Steen PA, Thoresen M 2003 Effect of global hypoxia-ischaemia followed by $24 \mathrm{~h}$ of mild hypothermia on organ pathology and biochemistry in a newborn pig survival model. Biol Neonate 83:146-156

20. Campbell I 2007 Chi-squared and Fisher-Irwin tests of two-by-two tables with small sample recommendations. Stat Med 26:3661-3675

21. Edwards AD, Brocklehurst P, Gunn AJ, Halliday H, Juszczak E, Levene M, Strohm B, Thoresen M, Whitelaw A, Azzopardi D 2010 Neurological outcomes at 18 months of age after moderate hypothermia for perinatal hypoxic ischaemic encephalopathy: synthesis and meta-analysis of trial data. BMJ 340:c363

22. Karlsson M, Tooley JR, Satas S, Hobbs CE, Chakkarapani E, Stone J, Porter H, Thoresen M 2008 Delayed hypothermia as selective head cooling or whole body cooling does not protect brain or body in newborn pig subjected to hypoxiaischemia. Pediatr Res 64:74-78

23. Thoresen M, Simmonds M, Satas S, Tooley J, Silver IA 2001 Effective selective head cooling during posthypoxic hypothermia in newborn piglets. Pediatr Res 49:594-599

24. Haaland K, Loberg EM, Steen PA, Thoresen M 1997 Posthypoxic hypothermia in newborn piglets. Pediatr Res 41:505-512

25. National Institute for Health and Clinical Excellence 2010 Therapeutic hypothermia with intracorporeal temperature monitoring for hypoxic perinatal brain injury. Available at: http://www.nice.org.uk/nicemedia/live/11315/48809/48809.pdf. Accessed June 13, 2011

26. Polderman KH 2008 Induced hypothermia and fever control for prevention and treatment of neurological injuries. Lancet 371:1955-1969

27. Gressens P, Dingley J, Plaisant F, Porter H, Schwendimann L, Verney C, Tooley J, Thoresen M 2008 Analysis of neuronal, glial, endothelial, axonal and apoptotic markers following moderate therapeutic hypothermia and anesthesia in the developing piglet brain. Brain Pathol 18:10-20

28. Panteghini M, Bonora R, Pagani F, Buffoli F, Cuccia C 1997 Rapid, highly sensitive immunoassay for determination of cardiac troponin I in patients with myocardial cell damage. Clin Chem 43:1464-1465

29. Hunkeler NM, Kullman J, Murphy AM 1991 Troponin I isoform expression in human heart. Circ Res 69:1409-1414

30. Bertsch T, Janke C, Denz C, Weiss M, Luiz T, Ellinger K, Korth U, Hannak D, Bartelt U, Krieter H 2000 Cardiac troponin I and cardiac troponin T increases in pigs during ischemia-reperfusion damage. Exp Toxicol Pathol 52:157-159

31. York M, Scudamore C, Brady S, Chen C, Wilson S, Curtis M, Evans G, Griffiths W, Whayman M, Williams T, Turton J 2007 Characterization of troponin responses in isoproterenol-induced cardiac injury in the Hanover Wistar rat. Toxicol Pathol 35:606-617

32. Taggart DP, Hadjinikolas L, Hooper J, Albert J, Kemp M, Hue D, Yacoub M, Lincoln JC 1997 Effects of age and ischemic times on biochemical evidence of myocardial injury after pediatric cardiac operations. J Thorac Cardiovasc Surg 113:728-735

33. Zhou WH, Shao XM, Zhang XD, Chen C, Huang GY 2003 [Effects of hypothermia on cardiac function in neonates with asphyxia]. Zhonghua Er Ke Za Zhi 41:460-462

34. Mavroudis C, Backer CL 2003 Pediatric Cardiac Surgery. Mosby, Philadelphia, pp $39-46$

35. Donnelly WH, Bucciarelli RL, Nelson RM 1980 Ischemic papillary muscle necrosis in stressed newborn infants. J Pediatr 96:295-300

36. Chakkarapani E, Dingley J, Liu X, Hoque N, Aquilina K, Porter H, Thoresen M 2010 Xenon enhances hypothermic neuroprotection in asphyxiated newborn pigs. Ann Neurol 68:330-341 